\title{
Negative Regulation of Human Pregnane X Receptor by MicroRNA-18a-5p: Evidence for Suppression of MicroRNA-18a-5p Expression by Rifampin and Rilpivirine ${ }^{\$}$
}

\author{
Devinder Sharma, Abdullah A. Turkistani, Wenjun Chang, Catherine Hu, Zhaoming Xu, \\ and Thomas K. H. Chang
}

Faculty of Pharmaceutical Sciences, (D.S., A.A.T., C.H., T.K.H.C.), and Food, Nutrition, and Health Program, Faculty of Land and Food Systems (W.C., Z.X.), The University of British Columbia, Vancouver, British Columbia, Canada

Received September 19, 2016; accepted April 4, 2017

\begin{abstract}
Small noncoding microRNAs act as post-transcriptional regulators of gene expression involved in diverse biologic functions. Pregnane $X$ receptor (PXR, NR1I2), a member of the superfamily of nuclear receptors, is a transcription factor governing the transport and biotransformation of various drugs and other chemicals. In the present study, we identified a specific microRNA (miR) involved in regulating the expression and functionality of human PXR (hPXR). According to bioinformatics analysis employing three commonly used algorithms (TargetScan, miRanda, and DIANA-microT-CDS), miR-18a-5p was predicted to be the top candidate microRNA regulator of hPXR. Consequently, this microRNA was selected for detailed experimental investigation. As shown in cell-based dual-luciferase reporter gene assays, functional interaction occurred between miR-18a-5p and the
\end{abstract}

microRNA recognition element of miR-18a-5p in the $3^{\prime}$-untranslated region of $h P X R$ mRNA. Transfection of LS180 human colorectal adenocarcinoma cells with an miR-18a-5p mimic decreased $h P X R$ mRNA and protein expression, whereas transfection of LS180 cells with an miR-18a-5p inhibitor increased hPXR mRNA and protein expression. The decrease in $h P X R$ expression by the miR-18a-5p mimic was associated with a reduction in the extent of $\mathrm{hPXR}$ target gene (CYP3A4) induction by rifampin and rilpivirine. Treatment of untransfected LS180 cells with either of these hPXR agonists decreased endogenous expression of miR-18a-5p, and this preceded the onset of CYP3A4 induction. In conclusion, miR-18a-5p is a negative regulator of $\mathrm{hPXR}$ expression and the $\mathrm{hPXR}$ agonists rifampin and rilpivirine are chemical suppressors of miR-18a-5p expression.

\section{Introduction}

Consisting of approximately 17-25 nucleotides (Wang et al., 2013), microRNAs (miR) are small noncoding RNAs present not only intracellularly but also in various body fluids, including blood and urine (Beermann et al., 2016). By their action on modulating mRNA degradation or translational repression (Iwakawa and Tomari, 2015), microRNAs control the post-transcriptional regulation of genes participating in various physiologic and pathophysiological processes, such as development and differentiation, metabolism, etiology of many cancers, and certain infections (Hammond, 2015). Emerging evidence suggests a potentially important role for microRNA in drug absorption, distribution, metabolism, and excretion, as indicated by findings that various drug-metabolizing enzymes, drug transporters, and associated nuclear receptors are targets of specific microRNAs (Dluzen and Lazarus, 2015; He et al., 2015).

This research was supported by the Natural Sciences and Engineering Research Council of Canada [Grant 2014-03734]. A.A.T. received a King Saud Scholarship, Ministry of Higher Education, Saudi Arabia.

https://doi.org/10.1124/mol.116.107003.

S This article has supplemental material available at molpharm. aspetjournals.org.
Pregnane X receptor (PXR, designated as NR1I2) belongs to the superfamily of nuclear receptors and is a member of the NR1I subfamily that includes vitamin D receptor (VDR, designated as NR1I1) and constitutive androstane receptor (CAR, designated as NR1I3) (Alexander et al., 2015). PXR has been linked to diverse biologic processes, ranging from energy metabolism (Gao and Xie, 2010) to various pathophysiological conditions, such as inflammatory bowel disease (Shah et al., 2007), bile acid toxicity (Staudinger et al., 2001), and dyslipidemia (Gao and Xie, 2012). It also controls the expression of various genes encoding transporters and drug-metabolizing enzymes involved in the distribution and elimination of endobiotics and xenobiotics (Chai et al., 2013). Studies over the past decade have shown a complex network of transcriptional, posttranscriptional, and post-translational mechanisms regulating the expression and action of human PXR (hPXR) (Staudinger et al., 2011; Smutny et al., 2013).

Over 500 human microRNAs have been deemed to meet the criteria for microRNA annotation (Fromm et al., 2015). However, relatively little is known about the identity of individual microRNAs involved in the regulation of hPXR (Dluzen and Lazarus, 2015). In a previous study on a panel of 25 human liver

ABBREVIATIONS: 3'-UTR, 3'-untranslated region; CAR, constitutive androstane receptor; DMSO, dimethyl sulfoxide; HPRT, hypoxanthine phosphoribosyltransferase 1; hPXR, human pregnane X receptor; miR, microRNA; MEM, minimum essential medium; MRE, microRNA recognition element; PCR, polymerase chain reaction; PXR, pregnane $\mathrm{X}$ receptor; VDR, vitamin $\mathrm{D}$ receptor. 
samples, the levels of hPXR mRNA expression did not correlate with the levels of hPXR protein expression, suggesting the involvement of a post-transcriptional mechanism(s) in hPXR expression (Takagi et al., 2008). As determined in a cell-based reporter gene assay, miR-148a was shown to regulate $\mathrm{hPXR}$ expression by binding to microRNA recognition elements (MRE) in the $3^{\prime}$-untranslated region ( 3 '-UTR) of hPXR mRNA (Takagi et al., 2008). In a panel of 24 liver samples from the Chinese Han population, a lack of correlation was demonstrated between miR-148a levels and hPXR translational efficiency, as assessed by the ratio of hPXR protein/hPXR mRNA (Wei et al., 2013). Similarly, miR-148a levels did not correlate with hPXR mRNA or CYP3A4 mRNA levels in a cohort of 92 liver samples from Caucasians (Rieger et al., 2013). Other studies have implicated miR-30c-1-3p (Vachirayonstien and Yan, 2016), miR-34a (Ramamoorthy et al., 2012; Lamba et al., 2014), and miR-449a (Ramamoorthy et al., 2012) in the regulation of hPXR. Overall, much remains to be investigated to identify individual microRNAs as determinants of the expression and functionality of $h P X R$.

Given that a single mRNA can be targeted by multiple microRNAs (Kim, 2005), the present study was performed to identify a novel microRNA as a regulator of hPXR. Therefore, we performed bioinformatics analysis to identify microRNAs with sequence complementary to the 3 '-UTR of hPXR mRNA and conducted a series of cell-based assays to determine the effect of a select microRNA on the expression and functionality of hPXR. The experimental approaches involved in silico prediction, cell-based reporter gene assay, mimic and inhibitor of microRNAs to modulate microRNA expression, and hPXR and CYP3A4 (a hPXR target gene) expression assays. Our novel results indicate negative regulation of $\mathrm{hPXR}$ expression by microRNA-18a-5p and suppression of miR-18a-5p expression by the hPXR agonists rifampin and rilpivirine.

\section{Materials and Methods}

Chemicals and Reagents. TaqMan microRNA Assay Kit for hsamiR-18a-5p (miR-18a-5p) (cat. no. 4427975, assay ID no. 002422) and hsa-miR-16-5p (miR-16-5p) (cat. no. 4427975, assay ID no. 000391); mirVana microRNA Mimic Negative, Control \#1 (mimic control) (cat. no. 4464058); hsa-miR-18a-5p mirVana microRNA Mimic (miR-18a5p mimic) (cat. no. 4464066, assay ID no. MC12973); mirVana microRNA Inhibitor Negative, Control \#1 (mimic control) (cat. no. 4464076); hsa-miR-18a-5p mirVana MicroRNA Inhibitor (miR-18a-5p inhibitor) (cat. no. 4464084, assay ID no. MH12973); hsa-miR-16-5p mirVana MicroRNA Mimic (miR-16-5p mimic) (cat. no. 4464066, assay ID no. MC10339); TaqMan MicroRNA Reverse Transcription Kit (cat. no. 4366596); Qubit RNA HS Assay Kit (cat. no. Q32855); TRIzol Reagent; SuperSignal West Femto Maximum Sensitivity Substrate; PicoGreen Double-Stranded DNA Quantification Kit; Lipofectamine RNAiMAX; Lipofectamine 2000; and UltraPure distilled water were purchased from Life Technologies/Thermo Fisher Scientific (Burlington, ON, Canada). EvaGreen $2 \times$ qPCR MasterMix-ROX and TaqProbe $2 \times$ qPCR MasterMix-ROX were bought from Applied Biologic Materials (Richmond, BC, Canada). The Dual-Luciferase Reporter Assay System and P450-Glo CYP3A4 (Luciferin-IPA) Assay Kit were from Promega (Madison, WI). Recombinant human PXR, CAR, and VDR proteins were purchased from OriGene Technologies (Rockville, MD). Anti-hPXR H-11 primary antibody, horseradish peroxidase-conjugated anti-mouse secondary antibody (sc-2005), and RIPA Lysis Buffer System were purchased from Santa Cruz Biotechnology (Dallas, TX), and the anti- $\beta$-actin antibody (TA306308) was purchased from OriGene Technologies. DC Protein Assay Kit was purchased from Bio-Rad Laboratories (Mississauga, ON, Canada).
Plasmids. The internal control Renilla reniformis luciferase pGL4.74 [hRluc/TK] plasmid and the pGL3-promoter vector were purchased from Promega. The portion of hPXR mRNA from +1041 to +1064 upstream of the coding sequence was identified as an miR-18a-5p MRE using www.microRNA.org, an online bioinformatics tool (Betel et al., 2008). The predicted MRE of miR-18a-5p (three copies of 5 '-GGT-ACC-GAAGAA-CCA-TTT-ACA-TGC-ACC-TTA-GAA-GAA-CCA-TTT-ACATGC-ACC-TTA-GAA-GAA-CCA-TTT-ACA-TGC-ACC-TTA-CTCGAG-3'; hPXR-MRE-18a-5p is underlined and italicized) in the $3^{\prime}$ UTR of hPXR mRNA was amplified and cloned into the pGL3-promoter vector using $K p n 1$ and Xho 1 restriction sites downstream of the luciferase gene. This construct was named pGL3-promoter-hPXRMRE18a-5p. Similarly, three copies of the complementary sequence of miR-18a-5p MRE (5'-GGT-ACC-CTT-CTT-GGT-AAA-TGT-ACGTGG-AAT-CTT-CTT-GGT-AAA-TGT-ACG-TGG-AAT-CTT-CTT-GGTAAA-TGT-ACG-TGG-AAT-CTC-GAG-3'; complementary sequence of miR-18a-5p is underlined and italicized) was amplified and cloned into the pGL3-promoter vector. This construct was named pGL3-promoterhPXR-MRE18a-5p-REV. A portion containing perfect matching sequence of the mature miR-18a-5p (5'-GGT-ACC-CTA-TCT-GCACTA-GAT-GCA-CCT-TAC-TCG-AG-3'; complementary-18a-5p is underlined and italicized) was amplified and cloned into the pGL3-promoter vector. This construct was named pGL3-promoter-complementary-18a-5p. Each of these constructs was synthesized at GenScript (Piscataway, NJ).

Cell Culture. LS180 human colorectal adenocarcinoma cells (CL187) (American Type Culture Collection, Manassas, VA) were cultured as described previously (Yeung et al., 2008), with the exception that minimum essential medium (MEM)/Earle's balanced salt solution was the culture medium and MEM/nonessential amino acid $(1 \times)$ was added. All cell-based assays were conducted in supplemented culture medium containing $10 \% \mathrm{v} / \mathrm{v}$ charcoal-stripped fetal bovine serum.

Transient Transfection and Luciferase Reporter Gene Assays. A microRNA mimic is a small, chemically modified doublestranded RNA used experimentally to provide overexpression of a microRNA of interest (Schaeffer et al., 2012), whereas a microRNA inhibitor is a small, chemically modified single-stranded RNA molecule designed to bind specifically to and decrease the expression of an endogenous microRNA of interest (Laganà et al., 2014). The effects of an miR-18a-5p mimic and an miR-18a-5p inhibitor on the functionality of the 3 '-UTR of hPXR mRNA were investigated in transiently transfected LS180 cells, which were seeded in 24-well plates (Biolite, cat. no. 930186; Thermo Fisher Scientific, Burlington, ON, Canada) at a density of 100,000 cells per well in a volume of $0.5 \mathrm{ml}$ of the culture medium described above. At 24 hours post-plating, cells were transfected with $50 \mu$ l of a master transfection mix containing Lipofectamine 2000 transfection reagent $(1.5 \mu \mathrm{l} / \mathrm{well})$, serum-free Opti-MEM (44.5 $\mu \mathrm{l} /$ well), pGL4.74 [hRluc/TK] (internal control; $10 \mathrm{ng} / \mathrm{well}$ ), a construct containing the pGL3-promoter backbone ( $200 \mathrm{ng} / \mathrm{well})$, and either miR-18a-5p mimic (50 nM) or miR-18a-5p inhibitor (50 $\mathrm{nM}$ ) for 48 hours, according to the manufacturer's protocol. Control cells were transfected with the same concentration $(50 \mathrm{nM})$ of a mimic control or an inhibitor control. The pGL3-promoter-containing construct was: 1) pGL3-promoter-hPXR-MRE18a-5p, 2) pGL3-promoter-hPXR-MRE18a5p-REV, 3) pGL3-promoter-complementary-18a-5p, or 4) the control empty vector (pGL3-promoter). Firefly luciferase and Renilla reniformis (internal control) luciferase activities were quantified and normalized (Sharma et al., 2013).

Transfection and Drug Treatment of LS180 Cells for Determination of microRNA and mRNA Expression. LS180 cells were seeded in 100-mm culture dishes (cat. no. 430167; Corning Inc., Corning, NY) at a density of $1 \times 10^{6}$ cells per dish. At 24 hours postplating, cells were transfected with an miR-18a-5p mimic or an miR18a-5p inhibitor (at the final concentration and duration as specified in each figure legend) in a master transfection mix (1000 $\mu$ l) containing Lipofectamine RNAiMAX transfection reagent (15 $\mu \mathrm{l})$ and serumfree Opti-MEM. In specific experiments, transfected LS180 cells were treated with rifampin $(10 \mu \mathrm{M})$, rilpivirine $(5 \mu \mathrm{M})$, or dimethyl sulfoxide (DMSO; 0.1\% v/v; vehicle control) for 24 hours. Subsequently, cell 
samples were processed for determination of microRNA and mRNA expression as described below.

Isolation and Quantitation of Total RNA. Total RNA was isolated using TRIzol and quantified using the Qubit RNA HS Assay Kit. A working solution of Qubit RNA HS Reagent (1:200 dilution) was prepared in Qubit RNA HS Buffer. Samples were prepared by adding $1 \mu \mathrm{l}$ of total RNA to $199 \mu \mathrm{l}$ of a working solution of Qubit RNA HS Reagent. After brief mixing, samples were incubated at room temperature for 2 minutes. Total RNA was quantified in a Qubit 2.0 fluorometer at an excitation maximum wavelength of $644 \mathrm{~nm}$ (bandwidth, $45 \mathrm{~nm}$ ) and an emission maximum wavelength of $673 \mathrm{~nm}$ (bandwidth, $55 \mathrm{~nm}$ ).

Determination of miR-18a-5p and miR-16-5p Expression. Total RNA was reverse transcribed using primers specific for miR18a-5p or miR-16-5p (TaqMan microRNA Assay Kit, assay ID no. 002422 for miR-18a-5p and assay ID no. 000391 for miR-16-5p) and reagents supplied in the TaqMan microRNA Reverse Transcription Kit. Briefly, each $15 \mu \mathrm{l}$ of a reverse transcription reaction contained $5 \mu \mathrm{l}$ total RNA (100 ng total RNA), $3 \mu \mathrm{l}$ of $5 \times$ reverse transcription stem-loop primers specific for miR-18a-5p or miR-16-5p, and $7 \mu \mathrm{l}$ of reverse transcription master mix. The reverse transcription master mix contained $1 \mu \mathrm{l}$ (5 units) of MultiScribe Reverse Transcriptase, $1.5 \mu \mathrm{l}$ of $10 \times$ reverse transcription buffer, $0.19 \mu \mathrm{l}$ of RNAse inhibitor (3.8 units), $0.15 \mu \mathrm{l}$ of dNTP ( $1 \mathrm{mM}$ final concentration), and $4.16 \mu \mathrm{l}$ of UltraPure distilled water. Reverse transcription (RT) was conducted at $16^{\circ} \mathrm{C}$ for 30 minutes followed by $42^{\circ} \mathrm{C}$ for 30 minutes, $85^{\circ} \mathrm{C}$ for 5 minutes, and $4^{\circ} \mathrm{C}$ for 10 minutes. Polymerase chain reaction (PCR) was performed in a StepOnePlus Real-Time PCR System (Applied Biosystems, Burlington, ON, Canada). Each $20 \mu \mathrm{l}$ of a PCR reaction contained $10 \mu \mathrm{l}$ of TaqProbe $2 \times$ qPCR MasterMix-ROX, $1 \mu \mathrm{l}$ of $20 \times$ PCR primers specific for miR-18a-5p or miR-16-5p (TaqMan microRNA Assay Kit, assay ID no. 002422 for miR-18a-5p and assay ID no. 000391 for miR-16-5p), $1 \mu \mathrm{l}$ of the RT product, and $8 \mu \mathrm{l}$ of UltraPure distilled water. The PCR cycling condition was $95^{\circ} \mathrm{C}$ for 10 minutes followed by 40 cycles of $95^{\circ} \mathrm{C}$ for 15 seconds and $60^{\circ} \mathrm{C}$ for 60 seconds. The level of miR$18 \mathrm{a}-5 \mathrm{p}$ was quantified and normalized to that of miR-16-5p.

Determination of hPXR and CYP3A4 mRNA Expression. Total RNA was reverse transcribed and total cDNA concentrations were quantified (Sharma et al., 2013). hPXR cDNA, CYP3A4 cDNA, hypoxanthine phosphoribosyltransferase 1 (HPRT) cDNA, and cyclophilin cDNA were amplified using gene-specific primers (Lau et al., 2011; Sharma et al., 2015) in a StepOnePlus Real-Time PCR System. Each $20 \mu \mathrm{l}$ of a PCR reaction contained $10 \mu \mathrm{l}$ of EvaGreen $2 \times$ qPCR MasterMix-ROX, $5 \mu \mathrm{l}$ of gene-specific primers $(0.3 \mu \mathrm{M}$ final concentration), and $5 \mu \mathrm{l}$ of the RT product (i.e., $10 \mathrm{ng}$ total cDNA for the amplification of CYP3A4 cDNA and hPXR cDNA, 5 ng total cDNA for the amplification of HPRT cDNA, and $0.5 \mathrm{ng}$ total cDNA for the amplification of cyclophilin cDNA). The PCR cycling condition was $95^{\circ} \mathrm{C}$ for 10 minutes followed by 40 cycles of $95^{\circ} \mathrm{C}$ for 15 seconds, $55^{\circ} \mathrm{C}$ for 10 seconds, and $60^{\circ} \mathrm{C}$ for 50 seconds. The levels of hPXR and CYP3A4 mRNA were quantified and normalized to HPRT mRNA level and cyclophilin mRNA level (Lau et al., 2010; Sharma et al., 2015).

Immunoblot Analysis of hPXR Protein Expression. Wholecell lysate was prepared using the RIPA Lysis Buffer System. Total protein concentration in cell lysate was quantified using the DC Protein Assay Kit (Bio-Rad Laboratories). Whole-cell lysate (75 $\mu \mathrm{g}$ total cellular protein) was separated on $12 \%$ SDS-PAGE and transferred onto an Immobilon-P polyvinylidene fluoride membrane (EMD Millipore, Etobicoke, ON, Canada). After blocking in 5\% milk, the membrane was incubated overnight at $4^{\circ} \mathrm{C}$ with anti-hPXR H-11 monoclonal antibody (1:500). Subsequently, the membrane was washed and incubated at room temperature with a horseradish peroxidase-conjugated anti-mouse antibody (1:5000). Proteins were visualized using SuperSignal West Femto Maximum Sensitivity Substrate $(600 \mu \mathrm{l})$ and images of the protein bands were recorded (FluorChem 8800 Gel Box Imager; Alpha Innotech, San Leandro, CA). Densitometric analysis of each protein band was performed using the NIH ImageJ software (National Institutes of Health, Bethesda, MD). $\beta$-Actin (OriGene Technologies, Rockville, $\mathrm{MD})$ was used as a loading control.
Determination of CYP3A4 Activity. CYP3A4 activity was measured using the P450-Glo CYP3A4 (Luciferin-IPA) Assay Kit. Briefly, LS180 cells were plated in 24-well plates at a density of 150,000 cells per well using supplemented MEM/Earle's balanced salt solution culture medium as indicated above. At 24 hours post-plating, cells were transfected with $50 \mathrm{nM}$ mimic control or an miR-18a-5p mimic using Lipofectamine RNAiMAX transfection reagent. At 48 hours post-transfection, the culture medium was replaced with $0.5 \mathrm{ml}$ of fresh supplemented culture medium containing a CYP3A4 inducer $(10 \mu \mathrm{M}$ rifampin or $5 \mu \mathrm{M}$ rilpivirine) or DMSO $(0.1 \% \mathrm{v} / \mathrm{v}$; vehicle control $)$ and incubated for 24 hours. At the end of the treatment period, culture medium in each well was replaced with $0.3 \mathrm{ml}$ of medium containing $3 \mu \mathrm{M}$ CYP3A4 Luciferin-IPA substrate, and cells were incubated at $37^{\circ} \mathrm{C}$ for 1 hour. Subsequently, $50 \mu \mathrm{l}$ of the incubation mixture was mixed with $50 \mu \mathrm{l}$ of the Luciferin Detection Reagent. Reaction mixtures were incubated at room temperature for 20 minutes. Luminescence was measured in a GloMax 96 microplate luminometer (Promega). Background luminescence was measured in wells devoid of cells but containing the Luciferin-IPA substrate. Results are expressed as fold-increase over the vehicle-treated control group.

Data Analysis. In experiments where there were two groups, data were analyzed by the two-tailed, independent Student's $t$ test. In experiments where there were two factors, data were analyzed by twoway analysis of variance and, where appropriate, followed by the Student-Newman-Keuls multiple comparison test (SigmaPlot 11.0; Systat Software, Inc., San Jose, CA). The level of statistical significance was set a priori at $P<0.05$.

\section{Results}

Prediction of miR-18a-5p MRE in the 3'-UTR of hPXR mRNA. As shown in Supplemental Table S1, miR-18a-5p was the top candidate microRNA regulator of hPXR, as predicted by three of the most commonly used bioinformatics tools in microRNA analysis: TargetScan (Whitehead Institute for Biomedical Research, Cambridge, MA; http://www.targetscan.org), miRanda (http://www.microrna.org), and DIANAmicroT-CDS (OMIC Tools, Le-Petit-Quevilly, France; https:// omictools.com) (Riffo-Campos et al., 2016). The predicted MRE of miR-18a-5p in the 3 '-UTR of hPXR mRNA ranged from position 1041 to 1064 upstream of the coding sequence (Fig. 1). This information about the MRE was used in designing various reporter plasmids to investigate the potential involvement of miR-18a-5p in regulation of the 3 '-UTR of $h P X R$ mRNA.

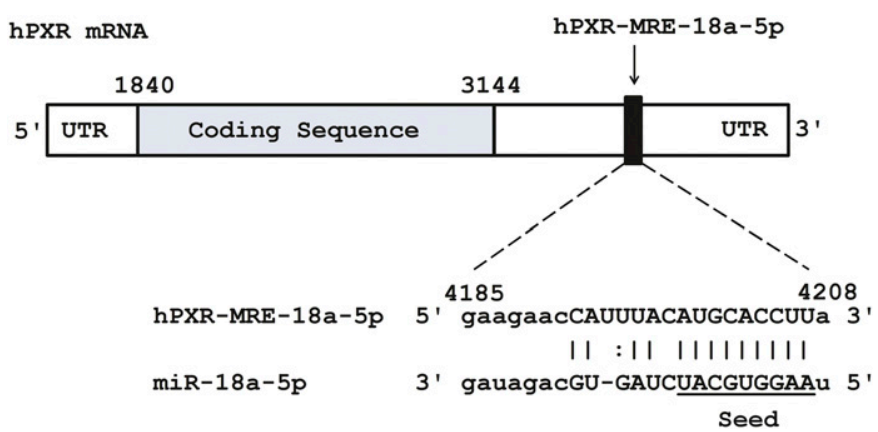

Fig. 1. Schematic representation of the sequence complementarity between miR-18a-5p and the predicted MRE on the 3'-UTR of hPXR mRNA. At the 5' end, number 1840 refers to the start of the coding sequence that continues to position 3141, with a stop codon at 3142-3144. The predicted MRE for miR-18a-5p (23-nucleotide sequence) is located at position 1041-1064 upstream to the coding sequence in the 3 '-UTR of hPXR mRNA. 
The miR-18a-5p MicroRNA Targeted the 3'-UTR of hPXR mRNA in LS180 Cells. Plasmids were cloned into the pGL3-promoter vector downstream of the luciferase gene (Fig. 2A). As shown in Fig. 2B, the luciferase activity was less in cultured LS180 cells cotransfected with an miR-18a-5p mimic and pGL3-promoter-hPXR-MRE-18a-5p than the luciferase activity in cells cotransfected with an miR-18-5p mimic and pGL3-promoter (empty vector control) or in cells cotransfected with a mimic control and pGL3-promoter-hPXR-MRE18a-5p (construct containing three copies of miR-18a-5p MRE). There was a further decrease in luciferase activity in cells cotransfected with an miR-18a-5p mimic and pGL3-promotercomplementary-18a-5p (construct with perfect matching complement of miR-18a-5p). As expected, the miR-18a-5p mimic did not influence the luciferase activity in cells transfected with pGL3-promoter-hPXR-MRE-18a-5p-REV (construct containing three copies of the complementary sequence of miR-18a-5p MRE). As shown in Fig. 2C, the luciferase activity was greater in cultured LS180 cells cotransfected with an miR-18a-5p inhibitor and pGL3-promoter-hPXR-MRE-18a-5p than the luciferase activity in cells cotransfected with an miR-18-5p mimic and pGL3-promoter or in cells cotransfected with a mimic control and pGL3-promoter-hPXR-MRE-18a-5p. There was a further increase in luciferase activity in cells cotransfected with an miR18a-5p mimic and pGL3-promoter-complementary-18a-5p. As expected, the miR-18a-5p inhibitor did not influence the luciferase activity in cells transfected with pGL3-promoter-hPXR-MRE18a-REV-5p. Collectively, the results from the complementary experiments involving miR-18-5p mimic (Fig. 2B) and miR-18a$5 p$ inhibitor (Fig. 2C) showed that the miR-18a-5p MRE in the 3'-UTR of hPXR mRNA was functional.

Expression Profile of miR-18a-5p in LS180 Cells Transfected with a Mimic or Inhibitor of miR-18a5p. Initial experiments confirmed that transfection reagent, mimic control, and treatment with either rilpivirine or rifampin did not alter miR-16-5p level (data not shown). Therefore, the level of miR-18a-5p was normalized to that of miR-16-5p. Transfection of LS180 cells with an miR-18a-5p mimic (25 nM) led to an increase in miR-18a-5p expression, as assessed 24 hours post-transfection. Prolonging the duration of transfection to
A

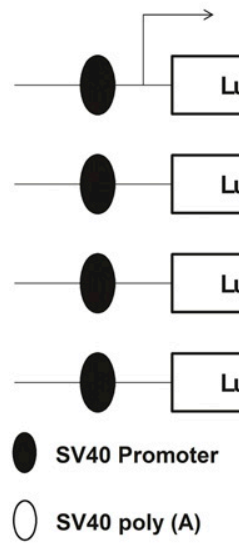

MRE: microRNA Recognition Element

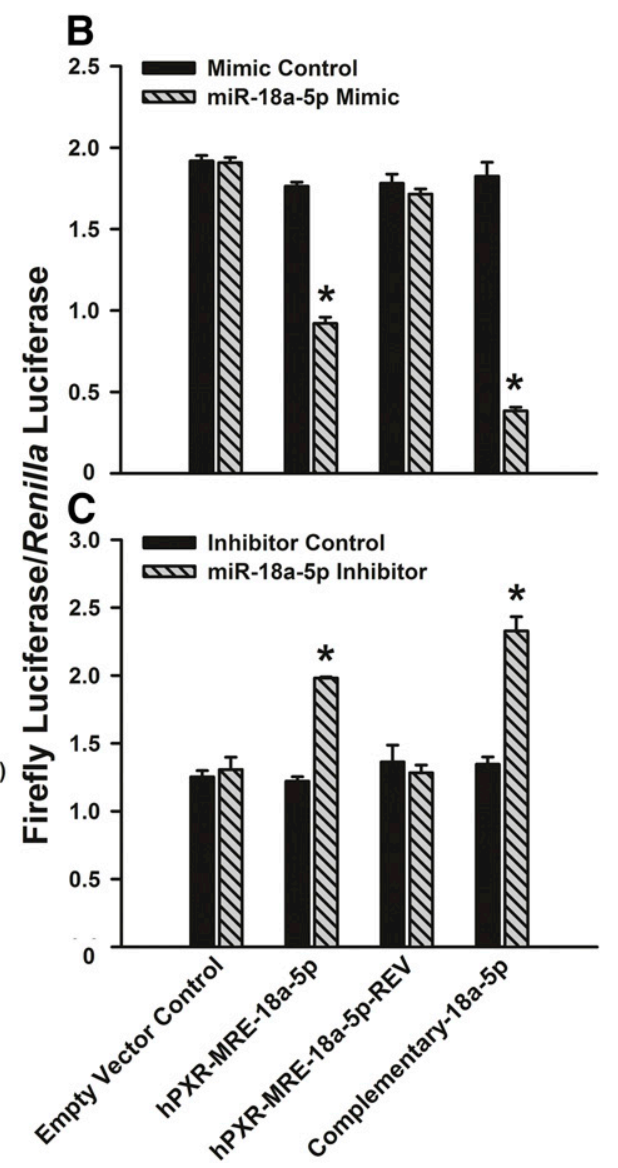

3 Copies of hPXR-MRE-18a-5p Sequence (hPXR-MRE-18a-5p)

IV 3 Copies of Complementary Sequence of hPXR-MRE-18a-5p (hPXR-MRE-18a-5p-REV) miR-18a-5p Perfect Matching Complement (Complementary-18a-5p)
pGL3-Promoter (Empty Vector Control)

PXR-MRE-18a-5p

PPXR-MRE-18a-5p-REV Complementary-18a-5p$$
\text { ) }
$$

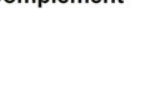

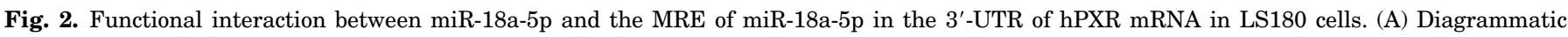

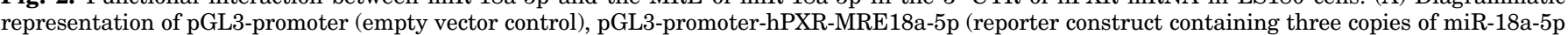

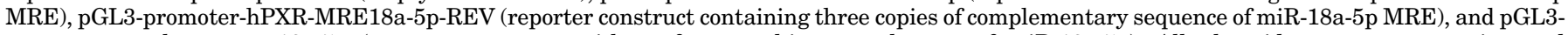

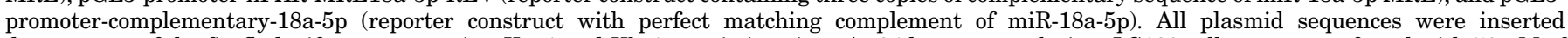

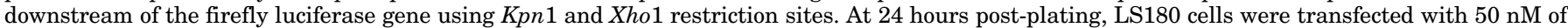

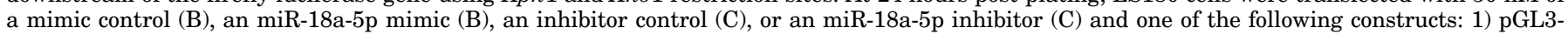

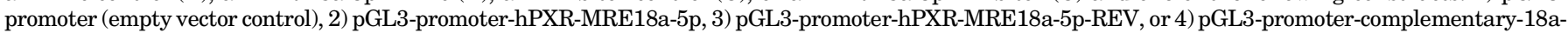

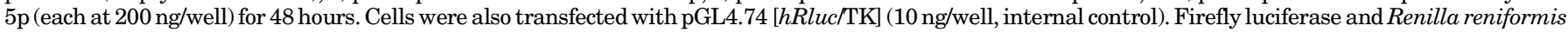

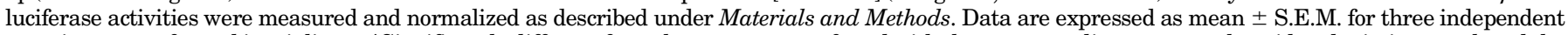

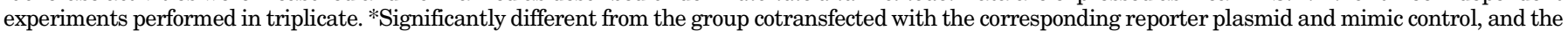
group cotransfected with the pGL3-promoter (empty vector control) and an miR-18a-5p mimic $(P<0.05)$. Luc, luciferase. 
48 and 72 hours decreased the measured level of miR-18a-5p, in comparison with the measured miR-18a-5p level at 24 hours (Fig. 3A). As shown in Fig. 3B, the increase in miR-18a-5p expression was comparable in cells transfected with either 25 or $50 \mathrm{nM}$ miR-18a-5p mimic for 48 hours (Fig. 3B). By comparison, transfection of LS180 cells with the miR-18a-5p inhibitor ( $25 \mathrm{nM})$ decreased the measured level of miR-18a-5p at 24, 48, and 72 hours post-transfection (Fig. 3C). Similar decreases in the level of miR-18a-5p were obtained with either 25 or $50 \mathrm{nM}$ miR-18a-5p inhibitor (Fig. 3D). On the basis of these results, the 48-hour transfection period and $50 \mathrm{nM}$ concentration of the miR-18a-5p mimic or inhibitor were used in subsequent experiments.

An miR-18a-5p Mimic and an miR-18a-5p Inhibitor Reciprocally Modulated hPXR Expression in LS180 Cells. The effects of an miR-18a-5p mimic and an miR-18a-5p inhibitor on hPXR expression were investigated. Transfecting LS180 cells with an miR-18a-5p mimic at a concentration ( 25 or $50 \mathrm{nM}$ ) that increased the level of miR-18a-5p (Fig. 3, A and $\mathrm{B}$ ) was associated with a decrease in the level of hPXR mRNA (Fig. 4A) and protein (Fig. 4B). Conversely, transfecting LS180 cells with an miR-18a-5p inhibitor at a concentration ( 25 or $50 \mathrm{nM}$ ) that decreased the level of miR-18a (Fig. 3, C and D) was associated with an increase in hPXR mRNA (Fig. 4C) and protein (Fig. 4D) levels. Control immunoblot analysis indicated that the anti-hPXR antibody reacted with hPXR protein, but it did not crossreact with human CAR or VDR protein (data not shown). Overall, miR-18a-5p modulated hPXR expression.

hPXR Agonists Decreased Endogenous Expression of miR-18a-5p in LS180 Cells. To investigate whether treatment with a hPXR agonist modulated endogenous expression of miR-18a-5p, a time course experiment was performed in untransfected LS180 cells treated with rifampin $(10 \mu \mathrm{M})$, rilpivirine $(5 \mu \mathrm{M})$, or DMSO $(0.1 \% \mathrm{v} / \mathrm{v}$; vehicle control) for 3,6 ,
12 , or 24 hours. As shown in Fig. 5A, rifampin decreased miR$18 \mathrm{a}-5 \mathrm{p}$ expression as early as 3 hours post-treatment and this decrease continued until 6 hours post-treatment. The level of miR-18a-5p returned to the basal level at 12 hours posttreatment. By comparison, rilpivirine started to decrease miR18a-5p level at 3 hours post-treatment, and levels returned to basal by 24 hours. The vehicle control ( $0.1 \% \mathrm{v} / \mathrm{v}$ DMSO) did not change the level of miR-18a-5p over the 24-hour period. In the same samples, rifampin and rilpivirine did not modulate hPXR mRNA level over the 24-hour time period (Fig. 5B). Control analysis indicated an increase in CYP3A4 mRNA level by rifampin and rilpivirine. However, a novel aspect of our data are the differential temporal profiles. As shown in Fig. 5C, the increase in CYP3A4 mRNA level in LS180 cells by rifampin occurred at 12 and 24 hours post-treatment, whereas it was not apparent until after 24 hours of rilpivirine treatment. The same conclusion was drawn regardless of whether the PXR mRNA and CYP3A4 mRNA levels were normalized to those of HPRT mRNA (Fig. 5, B and C) or cyclophilin mRNA (data not shown).

Overexpression of miR-18a-5p Compromised Inducibility of a hPXR Target Gene (CYP3A4) in LS180 Cells Treated with a hPXR Agonist. The effect of miR-18a-5p overexpression on hPXR functionality was investigated in LS180 cells transfected with the miR-18a-5p mimic and treated with a hPXR agonist, rifampin or rilpivirine. Compared with cells transfected with a mimic control and treated with rifampin or rilpivirine, the miR-18a-5p mimic attenuated the extent of CYP3A4 induction by either of these drugs, as shown by the reduced level of CYP3A4 mRNA (Fig. 6A) and CYP3A4 catalytic activity (Fig. 6B). The same conclusion was drawn regardless of whether the CYP3A4 mRNA level was normalized to that of HPRT mRNA (Fig. 6A) or cyclophilin mRNA (data not shown).

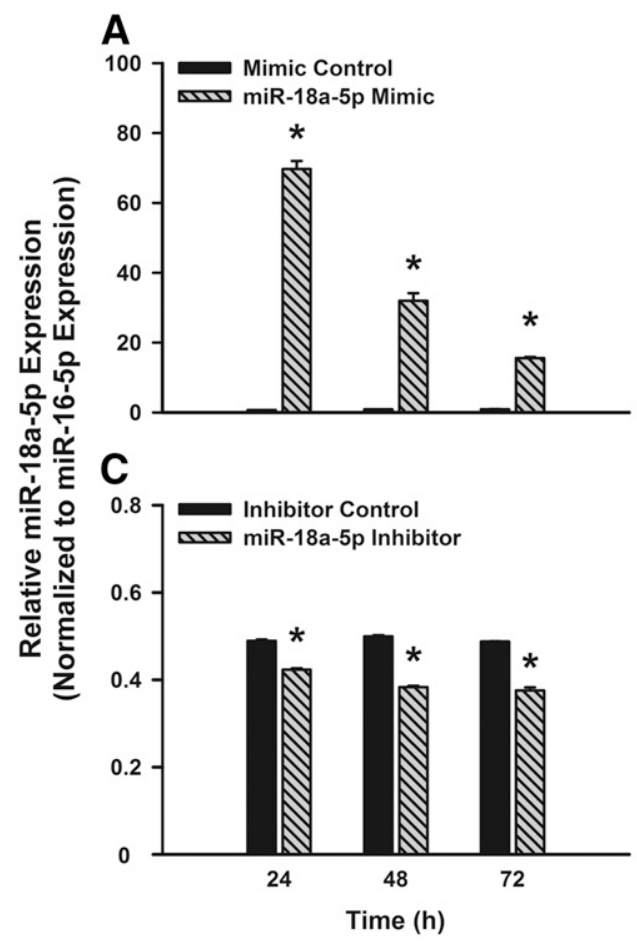

B

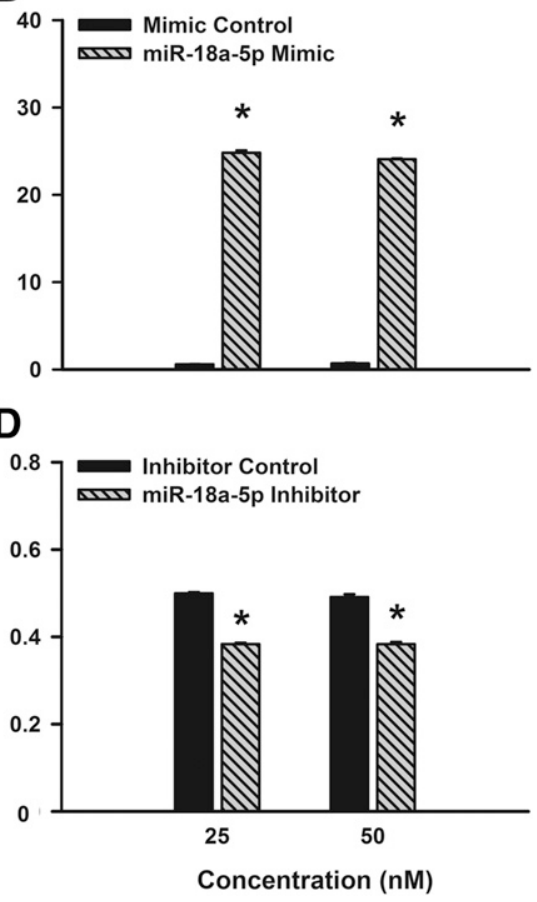

Fig. 3. Expression profile of miR-18a in LS180 cells transfected with an miR-18a-5p mimic or inhibitor. At 24 hours post-plating, LS180 cells were transfected with $25 \mathrm{nM}$ of a mimic control (A), an miR-18a-5p mimic (A), an inhibitor control (C), or an miR-18a-5p inhibitor (C) for 24,48 , or 72 hours. In another experiment, LS180 cells were transfected with 25 or $50 \mathrm{nM}$ of a mimic control (B), an miR-18a-5p mimic (B), an inhibitor control (D), or an miR-18a-5p inhibitor (D) for 48 hours. At the end of the transfection period, total RNA was isolated and miR-18a-5p and miR-16-5p expression were measured as described under Materials and Methods. The level of miR-18a-5p in each sample was normalized to the level of miR-16-5p. Data are expressed as mean \pm S.E.M. for three independent experiments performed in triplicate. *Significantly different from the corresponding mimic control group $(P<0.05)$. 


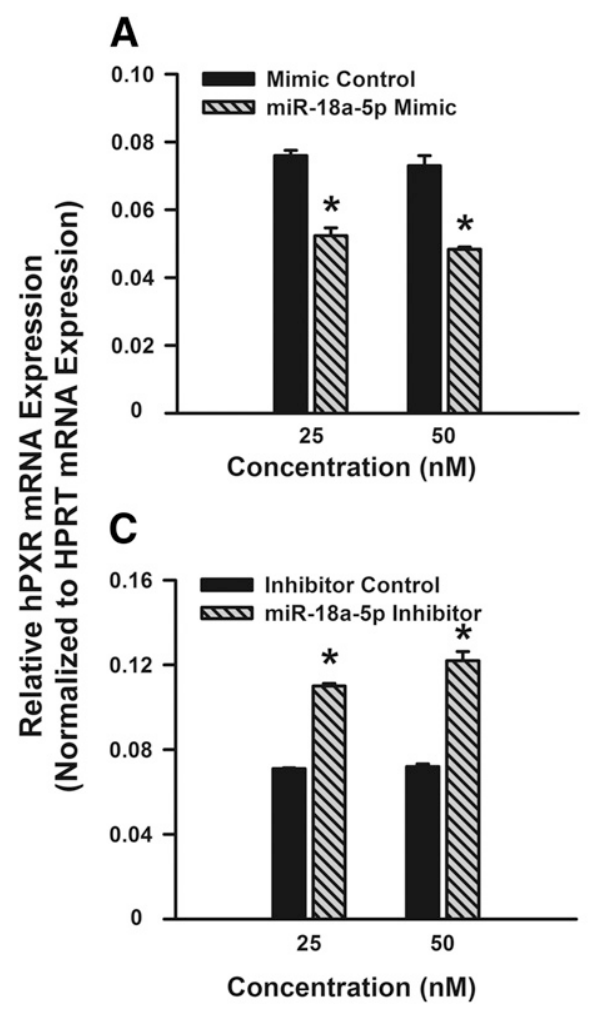

\section{Discussion}

The miR-18a-5p microRNA and the other members in the miR-17/92 cluster (miR-17-5p, miR-17-3p, miR-19a, miR-19b, miR-20a, and miR-92a) are oncogenes shown to be overexpressed in various types of human cancer (Mogilyansky and Rigoutsos, 2013). In a previous bioinformatics analysis using three algorithms (TargetScan, microcosm, and miRDB) and a microRNA ranking tool known as MIRNA-DISTILLER (Rieger et al., 2011; http://www.ikp-stuttgart.de/content/language1/html/10415.asp), hPXR was predicted to be a target of miR-18a-5p (Rieger et al., 2013), consistent with the prediction in our study (Supplemental Table S1). However, prior to our current study, there were no published experimental data indicating whether miR-18a-5p had any functional interaction with key regulators (e.g., hPXR) of genes involved in drug transport or biotransformation.

A major conclusion of our study is that miR-18a-5p is a posttranscriptional regulator of hPXR. This conclusion is supported by: 1) bioinformatics analysis of the $3^{\prime}$-UTR of hPXR mRNA identified a MRE for miR-18a-5p; 2) miR-18a-5p MRE in the 3'-UTR of hPXR mRNA was functional in a cell-based reporter gene assay; and 3) modulation of miR-18a-5p expression by a mimic or inhibitor altered hPXR expression in LS180 cells. It is possible that miR-18a-5p crosstalks with glucocorticoid receptor in mediating its modulatory effect on hPXR, on the basis of the finding that miR-18a-5p regulates the expression of glucocorticoid receptor (Vreugdenhil et al., 2009), shown previously to influence hPXR expression (Pascussi et al., 2001). However, LS180 cells do not express glucocorticoid receptor (Maier et al., 2007), nullifying the possibility of a role for the glucocorticoid receptor in hPXR regulation by miR-18a-5p in this cell line. Overall, our findings indicate that miR-18a-5p regulates hPXR expression by targeting its MRE in the 3 '-UTR of hPXR mRNA.
Regulation of hPXR expression by miR-18a-5p is associated with functional consequences, as demonstrated by the finding that overexpression of miR-18a by LS180 cells transfected with a mimic of miR-18a-5p compromised the inducibility of a hPXR target gene (CYP3A4). Consistent with this conclusion, transfection of LS180 cells with an miR-18a-5p mimic attenuated the increase in CYP3A4 mRNA expression and CYP3A4 catalytic activity by rifampin and rilpivirine, which are hPXR agonists and CYP3A4 inducers (Bertilsson et al., 1998; Lehmann et al., 1998; Sharma et al., 2013). In contrast, transfection with a mimic of miR-18a-5p did not alter CYP3A4 expression in vehicletreated control LS180 cells, suggesting a lack of a direct effect of miR-18a-5p on CYP3A4 basal expression. It should be noted that miR-18a-5p has sequence complementarity in the 3 '-UTR of hPXR mRNA but not in the $3^{\prime}$-UTR of CYP3A4 mRNA. Furthermore, basal CYP3A4 expression is regulated by CCAAT enhancer-binding protein $\alpha(\mathrm{C} / \mathrm{EBP} \alpha)$ (Rodríguez-Antona et al., 2003; Bombail et al., 2004), hepatocyte nuclear factor-3 $\gamma$ (Rodríguez-Antona et al., 2003), and hepatocyte nuclear factor$4 \alpha$ (Tegude et al., 2007). PXR does not appear to play a role in the basal expression of CYP3A because little or no difference exists in hepatic CYP3A mRNA level between untreated wild-type mice and untreated PXR knockout mice (Xie et al., 2000; Ma et al., 2007; Helsley et al., 2013). Overall, miR-18a-5p compromised the functionality of hPXR in LS180 cells by attenuating the inducibility of a hPXR target gene (CYP3A4).

As shown in the present study, transfection of LS180 cells with an miR-18a-5p mimic resulted in $~ 25$-fold increase in miR-18a-5p level and this was accompanied by $\sim 30 \%$ decrease in hPXR mRNA level. By comparison, a $25 \%$ decrease in miR18a-5p level in LS180 cells by an miR-18a-5p inhibitor was sufficient to elicit a 55\% increase in hPXR mRNA level. Such an apparent difference between a microRNA mimic and a 


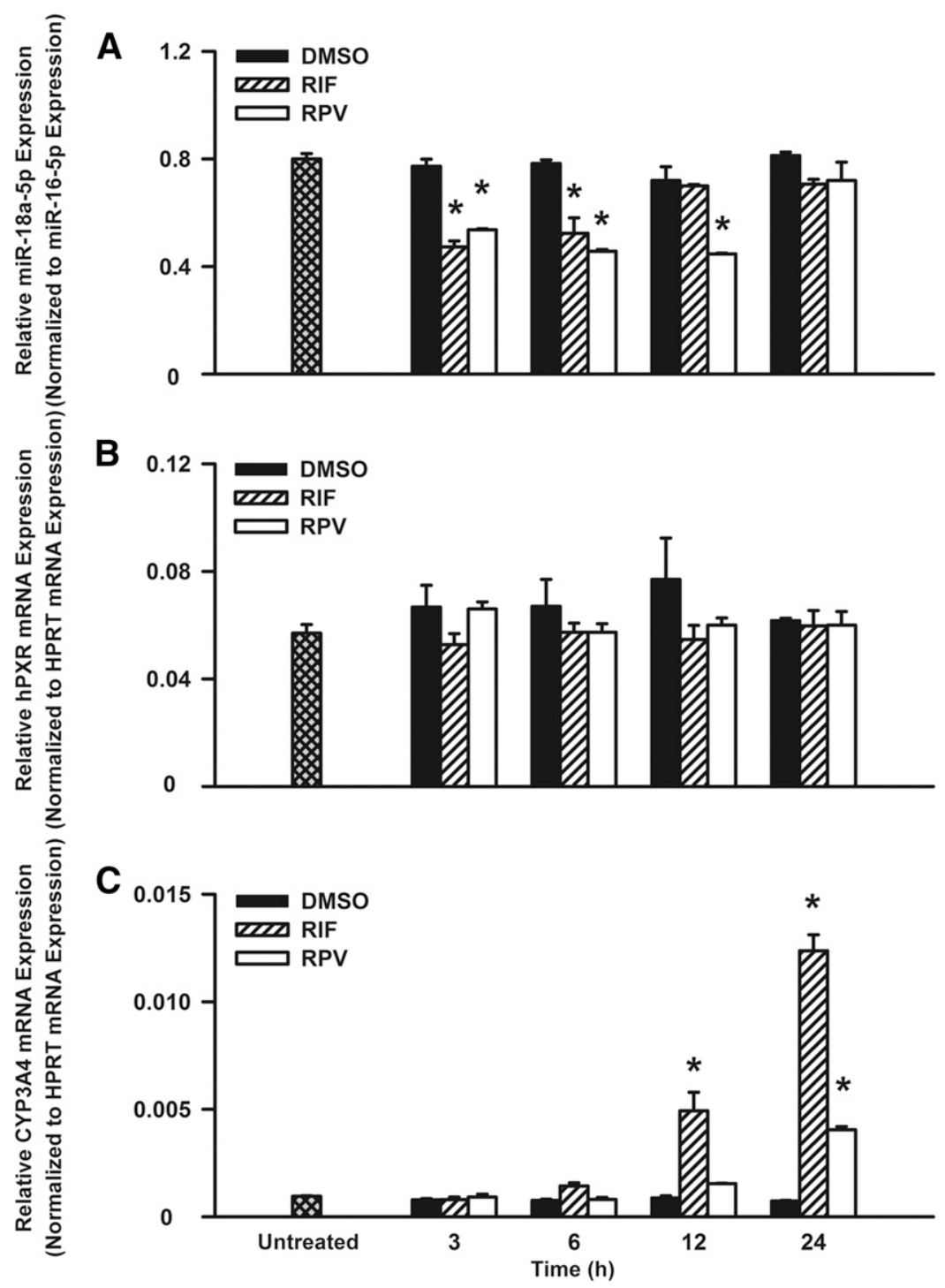

Fig. 5. Effect of rifampin and rilpivirine on endogenous expression of miR-18a-5p, hPXR mRNA, and CYP3A4 mRNA in untransfected LS180 cells. At 48 hours postplating, LS180 cells were untreated or treated with DMSO $(0.1 \% \mathrm{v} / \mathrm{v}$; control), rifampin (RIF; $10 \mu \mathrm{M})$, or rilpivirine (RPV; $5 \mu \mathrm{M}$ ) for $3,6,12$, or 24 hours. At the end of treatment period, cells were lysed and total RNA was isolated, and microRNA and mRNA levels were quantified by real-time PCR as described under Materials and Methods. The level of miR-18a-5p (A) was normalized to the level of miR-16-5p, whereas the level of PXR mRNA (B) and the level of CYP3A4 mRNA (C) were normalized to the level of HPRT mRNA. Data are expressed as mean \pm S.E.M. for three independent experiments performed in triplicate. *Significantly different from the untreated group and the corresponding DMSO-treated control group $(P<0.05)$.

microRNA inhibitor is consistent with previous observations. For example, transfection of HepaRG cells with an miR-25-3p mimic increased miR-25-3p levels by almost 175-fold but decreased CYP2B6 mRNA level by only $\sim 40 \%$, whereas transfection with an miR-25-3p inhibitor decreased miR-25$3 \mathrm{p}$ level $\sim 75 \%$ and this led to a $\sim 25 \%$ increase in CYP2B6
mRNA level (Jin et al., 2016). The low efficiency at which a microRNA mimic decreases the expression of a target has been shown for other combinations of microRNA mimic and target, including miR-148a mimic and hPXR (Takagi et al., 2008), miR-103 mimic and CYP2C8 (Zhang et al., 2012), and miR-130-3p mimic and sphingosine 1-phosphate receptor 2
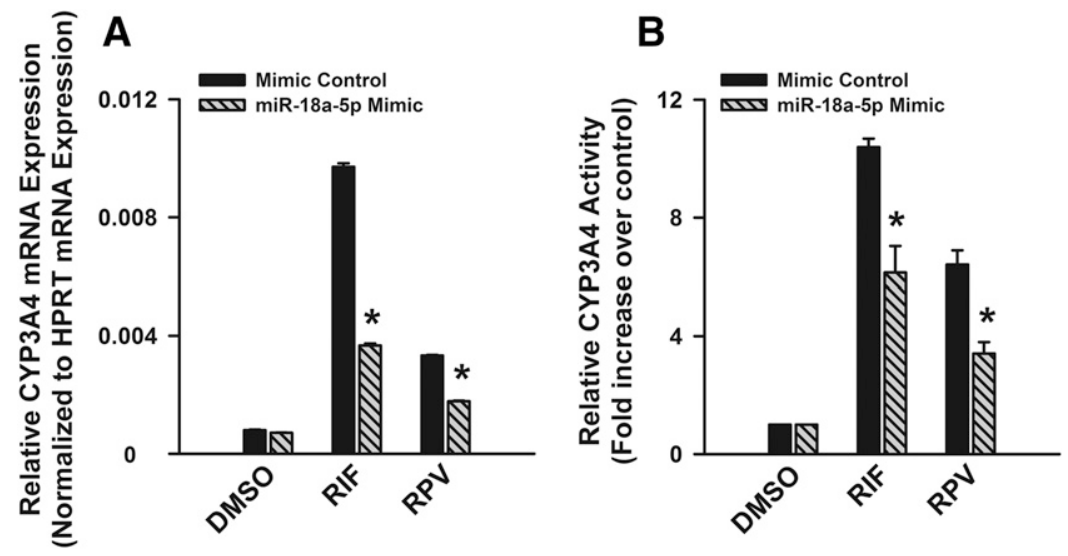

Fig. 6. Inducibility of a hPXR target gene (CYP3A4) in LS180 cells transfected with an miR-18a-5p mimic and treated with rifampin or rilpivirine. At 24 hours postplating, LS180 cells were transfected with $50 \mathrm{nM}$ of an miR-18a-5p mimic or a mimic control for 48 hours, and subsequently treated with DMSO $(0.1 \% \mathrm{v} / \mathrm{v})$, rifampin (RIF; $10 \mu \mathrm{M}$ ), or rilpivirine (RPV; $5 \mu \mathrm{M})$ for 24 hours. CYP3A4 mRNA (A) and CYP3A4 catalytic activity (B) were determined as described under Materials and Methods. Data are expressed as mean \pm S.E.M. for three independent experiments performed in triplicate. *Significantly different from the corresponding mimic control group $(P<0.05)$. 
(Fan et al., 2016). The underlying reason for the low efficiency of a microRNA mimic is presently not known, but it may relate to the chemical modification of the RNA molecule introduced in the synthesis of a mimic (Søkilde et al., 2015).

Several psychoactive drugs, including harmaline, which is an indole alkaloid, have been reported to decrease miR-18a-5p expression in cultured SH-SY5Y human neuroblastoma cells (Rodrigues et al., 2011). In the present study, the hPXR agonists rifampin and rilpivirine decreased the endogenous expression of miR-18a-5p in untransfected LS180 cells, and this occurred in a time-dependent manner and preceded the onset of induction of a hPXR target gene (CYP3A4) by rifampin and rilpivirine. The temporal profile obtained from our time course experiment indicated that the reduction in endogenous miR-18a-5p expression by the drugs was a relatively early event, which was evident at 3 hours post-drug treatment. The level of miR-18a-5p returned to baseline level by 12 hours after rifampin treatment and by 24 hours after rilpivirine treatment. Consistent with our finding, rifampin did not alter miR18a-5p level in human hepatocytes when assessed at 48 hours post-drug treatment in a microarray experiment (Takahashi et al., 2014). Therefore, it is necessary to include early time points to detect changes in endogenous expression of a microRNA. Although our study is the first to report modulation of microRNA expression by rilpivirine, previous microarray analyses have shown increased and decreased levels of various microRNAs by rifampin in primary cultures of human hepatocytes (Ramamoorthy et al., 2013; Takahashi et al., 2014). The mechanism of miR-18a-5p suppression by rifampin and rilpivirine is not known, but it may involve perturbation at one or more of the multiple steps involved in microRNA biogenesis, such as transcription, nuclear maturation, export from the nucleus to the cytoplasm, and cytoplasmic processing (Beermann et al., 2016). Post-transcriptional and epigenetic alterations are also key determinants governing microRNA expression (Wang et al., 2013). Future studies will be needed to elucidate the cellular and molecular mechanisms by which drugs and other chemicals modulate microRNA expression.

According to the current study, transfection of LS180 cells with an miR-18a-5p mimic decreased hPXR mRNA and protein expression when assessed at 48 hours post-transfection. In contrast, treatment of untransfected LS180 cells with rifampin or rilpivirine did not change hPXR mRNA level at 3, 6, 12, or 24 hours after drug treatment, but this was associated with an increase in CYP3A4 mRNA level at 12 and 24 hours postrifampin treatment and at 24 hours post-rilpivirine treatment. Consistent with our data, previous studies have also reported a lack of an effect of rifampin on hPXR mRNA and protein levels when assessed at 24 hours post-rifampin treatment in LS174T human colorectal carcinoma cells (Kim et al., 2017), IHH immortalized human hepatocytes (Berthier et al., 2012), and primary cultures of human hepatocytes (Ayed-Boussema et al., 2012). However, prolonging the exposure to rifampin to 72 hours is associated with an increase in hPXR expression, as demonstrated in T84 human colorectal carcinoma cells (Haslam et al., 2008). Therefore, it appears there is a lag time for the increase in hPXR expression to be evident, but a detailed time course study in the same cell culture model will be needed to characterize the temporal pattern. Adding to the intricacy, other cellular factors are probably associated with the interaction between microRNAs, nuclear receptors, and their target genes. For example, the downregulation of miR-122, activation of CAR, and induction of CAR target gene $(C Y P 2 B)$ by phenobarbital are associated with activation of AMP-activated protein kinase by the drug (Shizu et al., 2012). Therefore, studies will be required in the future to provide an understanding of how miR-18a-5p regulates the expression and functionality of $\mathrm{hPXR}$.

In summary: 1) miR-18a-5p was a post-transcriptional regulator of $\mathrm{hPXR}, 2$ ) overexpression of miR-18a-5p compromised the functionality of hPXR by attenuating the inducibility of a hPXR target gene (CYP3A4) by rifampin and rilpivirine, and 3) rifampin and rilpivirine decreased the endogenous expression of miR-18a-5p, as determined in the present study performed in LS180 human colon adenocarcinoma cells. Given that PXR is a master regulator of various genes function in drug transports and biotransformation (Chai et al., 2013), our finding on the interaction between miR-18a-5p and hPXR provides additional insight into the molecular determinants of the interindividual variability in pharmacokinetics and pharmacodynamics. Suppression of miR-18a-5p expression by rifampin and rilpivirine may have implications with respect to the proposed utility of miR-18a-5p as a diagnostic biomarker for various types of cancers (Komatsu et al., 2014), because of the potential interference of drug intake on miR-18a-5p expression. Finally, suppression of miR-18a-5p has been associated with inhibition of cell invasion and promote apoptosis (Zhu et al., 2015). Therefore, drug-mediated suppression of miR-18a-5p may be a target of interest in future investigations of anticancer strategies.

\section{Acknowledgments}

The authors thank Dr. Guixiang Yang for her guidance in designing the various constructs.

\section{Authorship Contributions}

Participated in research design: Sharma, Xu, T. K. H. Chang.

Conducted experiments: Sharma, Turkistani, W. Chang. Contributed new reagents or analytic tools: $\mathrm{Hu}$.

Performed data analysis: Sharma.

Wrote or contributed to the writing of the manuscript: Sharma, $\mathrm{Xu}$, T. K. H. Chang.

\section{References}

Alexander SP, Kelly E, Marrion N, Peters JA, Benson HE, Faccenda E, Pawson AJ, Sharman JL, Southan C, Buneman OP, et al.; CGTP Collaborators (2015) The concise guide to PHARMACOLOGY 2015/16: Overview. $\mathrm{Br} J$ Pharmacol 172: 5729-5743.

Ayed-Boussema I, Pascussi JM, Zaied C, Maurel P, Bacha H, and Hassen W (2012) Ochratoxin A induces CYP3A4, 2B6, 3A5, 2C9, 1A1, and CYP1A2 gene expression in primary cultured human hepatocytes: a possible activation of nuclear receptors. Drug Chem Toxicol 35:71-80.

Beermann J, Piccoli MT, Viereck J, and Thum T (2016) Non-coding RNAs in development and disease: background, mechanisms, and therapeutic approaches. Physiol Rev 96:1297-1325.

Berthier A, Oger F, Gheeraert C, Boulahtouf A, Le Guével R, Balaguer P, Staels B, Salbert G, and Lefebvre P (2012) The novel antibacterial compound walrycin A induces human PXR transcriptional activity. Toxicol Sci 127:225-235.

Bertilsson G, Heidrich J, Svensson K, Asman M, Jendeberg L, Sydow-Bäckman M, Ohlsson R, Postlind H, Blomquist P, and Berkenstam A (1998) Identification of a human nuclear receptor defines a new signaling pathway for CYP3A induction. Proc Natl Acad Sci USA 95:12208-12213.

Betel D, Wilson M, Gabow A, Marks DS, and Sander C (2008) The microRNA.org resource: targets and expression. Nucleic Acids Res 36:D149-D153.

Bombail V, Taylor K, Gibson GG, and Plant N (2004) Role of Sp1, C/EBP $\alpha$, HNF3, and PXR in the basal- and xenobiotic-mediated regulation of the CYP3A4 gene. Drug Metab Dispos 32:525-535.

Chai X, Zeng S, and Xie W (2013) Nuclear receptors PXR and CAR: implications for drug metabolism regulation, pharmacogenomics and beyond. Expert Opin Drug Metab Toxicol 9:253-266.

Dluzen DF and Lazarus P (2015) MicroRNA regulation of the major drug-metabolizing enzymes and related transcription factors. Drug Metab Rev 47:320-334.

Fan A, Wang Q, Yuan Y, Cheng J, Chen L, Guo X, Li Q, Chen B, Huang X, and Huang $\mathrm{Q}$ (2016) Liver X receptor- $\alpha$ and miR-130a-3p regulate expression of sphingosine 1-phosphate receptor 2 in human umbilical vein endothelial cells. Am J Physiol Cell Physiol 310:C216-C226. 
Fromm B, Billipp T, Peck LE, Johansen M, Tarver JE, King BL, Newcomb JM, Sempere LF, Flatmark K, Hovig E, et al. (2015) A uniform system for the annotation of vertebrate microRNA genes and the evolution of the human microRNAome. Annu Rev Genet 49:213-242.

Gao J and Xie W (2010) Pregnane X receptor and constitutive androstane receptor at the crossroads of drug metabolism and energy metabolism. Drug Metab Dispos 38: 2091-2095.

Gao J and Xie W (2012) Targeting xenobiotic receptors PXR and CAR for metabolic diseases. Trends Pharmacol Sci 33:552-558.

Hammond SM (2015) An overview of microRNAs. Adv Drug Deliv Rev 87:3-14.

Haslam IS, Jones K, Coleman T, and Simmons NL (2008) Rifampin and digoxin induction of MDR1 expression and function in human intestinal (T84) epithelial cells. Br J Pharmacol 154:246-255.

He Y, Chevillet JR, Liu G, Kim TK, and Wang K (2015) The effects of microRNA on the absorption, distribution, metabolism and excretion of drugs. $\mathrm{Br} J$ Pharmacol 172:2733-2747.

Helsley RN, Sui Y, Ai N, Park SH, Welsh WJ, and Zhou C (2013) Pregnane X receptor mediates dyslipidemia induced by the HIV protease inhibitor amprenavir in mice. Mol Pharmacol 83:1190-1199.

Iwakawa HO and Tomari Y (2015) The functions of microRNAs: mRNA decay and translational repression. Trends Cell Biol 25:651-665.

Jin Y, Yu D, Tolleson WH, Knox B, Wang Y, Chen S, Ren Z, Deng H, Guo Y, and Ning B (2016) MicroRNA hsa-miR-25-3p suppresses the expression and drug induction of CYP2B6 in human hepatocytes. Biochem Pharmacol 113:88-96.

Kim SW, Md Hasanuzzaman, Cho M, Kim NH, Choi HY, Han JW, Park HJ, Oh JW, and Shin JG (2017) Role of 14-3-3 sigma in over-expression of P-gp by rifampin and paclitaxel stimulation through interaction with PXR. Cell Signal 31:124-134.

Kim VN (2005) MicroRNA biogenesis: coordinated cropping and dicing. Nat Rev Mol Cell Biol 6:376-385.

Komatsu S, Ichikawa D, Takeshita H, Morimura R, Hirajima S, Tsujiura M Kawaguchi T, Miyamae M, Nagata H, Konishi H, et al. (2014) Circulating miR-18a: a sensitive cancer screening biomarker in human cancer. In Vivo 28:293-297.

Laganà A, Shasha D, and Croce CM (2014) Synthetic RNAs for gene regulation: design principles and computational tools. Front Bioeng Biotechnol 2:65.

Lamba V, Ghodke Y, Guan W, and Tracy TS (2014) microRNA-34a is associated with expression of key hepatic transcription factors and cytochromes P450. Biochem Biophys Res Commun 445:404-411.

Lau AJ, Yang G, Rajaraman G, Baucom CC, and Chang TKH (2010) Human pregnane X receptor agonism by Ginkgo biloba extract: assessment of the role of individual ginkgolides. J Pharmacol Exp Ther 335:771-780.

Lau AJ, Yang G, Rajaraman G, Baucom CC, and Chang TKH (2011) Differential effect of meclizine on the activity of human pregnane $\mathrm{X}$ receptor and constitutive androstane receptor. J Pharmacol Exp Ther 336:816-826.

Lehmann JM, McKee DD, Watson MA, Willson TM, Moore JT, and Kliewer SA (1998) The human orphan nuclear receptor PXR is activated by compounds that regulate CYP3A4 gene expression and cause drug interactions. J Clin Invest 102 $1016-1023$

Ma X, Shah Y, Cheung C, Guo GL, Feigenbaum L, Krausz KW, Idle JR, and Gonzalez FJ (2007) The PREgnane X receptor gene-humanized mouse: a model for investigating drug-drug interactions mediated by cytochromes P450 3A. Drug Metab Dispos 35:194-200.

Mogilyansky E and Rigoutsos I (2013) The miR-17/92 cluster: a comprehensive update on its genomics, genetics, functions and increasingly important and numerous roles in health and disease. Cell Death Differ 20:1603-1614.

Maier A, Zimmermann C, Beglinger C, Drewe J, and Gutmann H (2007) Effects of budesonide on P-glycoprotein expression in intestinal cell lines. $\mathrm{Br} J$ Pharmacol 150:361-368.

Pascussi JM, Drocourt L, Gerbal-Chaloin S, Fabre JM, Maurel P, and Vilarem MJ (2001) Dual effect of dexamethasone on CYP3A4 gene expression in human hepatocytes. Sequential role of glucocorticoid receptor and pregnane X receptor. Eur $J$ Biochem 268:6346-6358.

Ramamoorthy A, Li L, Gaedigk A, Bradford LD, Benson EA, Flockhart DA, and Skaar TC (2012) In silico and in vitro identification of microRNAs that regulate hepatic nuclear factor $4 \alpha$ expression. Drug Metab Dispos 40:726-733.

Ramamoorthy A, Liu Y, Philips S, Desta Z, Lin H, Goswami C, Gaedigk A, Li L, Flockhart DA, and Skaar TC (2013) Regulation of microRNA expression by rifampin in human hepatocytes. Drug Metab Dispos 41:1763-1768.

Rieger JK, Bodan DA, and Zanger UM (2011) MIRNA-DISTILLER: a stand-alone application to compile microRNA data from databases. Front Genet 2:39.

Rieger JK, Klein K, Winter S, and Zanger UM (2013) Expression variability of absorption, distribution, metabolism, excretion-related microRNAs in human liver: influence of nongenetic factors and association with gene expression. Drug Metab Dispos 41:1752-1762.

Riffo-Campos AL, Riquelme I, and Brebi-Mieville P (2016) Tools for sequence-based miRNA target prediction: What to choose? Int J Mol Sci 17:1987.
Rodrigues AC, Li X, Radecki L, Pan YZ, Winter JC, Huang M, and Yu AM (2011) MicroRNA expression is differentially altered by xenobiotic drugs in different human cell lines. Biopharm Drug Dispos 32:355-367.

Rodríguez-Antona C, Bort R, Jover R, Tindberg N, Ingelman-Sundberg M, GómezLechón MJ, and Castell JV (2003) Transcriptional regulation of human CYP3A4 basal expression by CCAAT enhancer-binding protein $\alpha$ and hepatocyte nuclear factor-3 $\gamma$. Mol Pharmacol 63:1180-1189.

Schaeffer V, Hansen KM, Morris DR, LeBoeuf RC, and Abrass CK (2012) RNAbinding protein IGF2BP2/IMP2 is required for laminin- $\beta 2$ mRNA translation and is modulated by glucose concentration. Am J Physiol Renal Physiol 303:F75-F82.

Shah YM, Ma X, Morimura K, Kim I, and Gonzalez FJ (2007) Pregnane X receptor activation ameliorates DSS-induced inflammatory bowel disease via inhibition of NF-kappaB target gene expression. Am J Physiol Gastrointest Liver Physiol 292: G1114-G1122.

Sharma D, Lau AJ, Sherman MA, and Chang TKH (2013) Agonism of human pregnane $\mathrm{X}$ receptor by rilpivirine and etravirine: comparison with first generation nonnucleoside reverse transcriptase inhibitors. Biochem Pharmacol 85:1700-1711.

Sharma D, Lau AJ, Sherman MA, and Chang TKH (2015) Differential activation of human constitutive androstane receptor and its SV23 and SV24 splice variants by rilpivirine and etravirine. Br J Pharmacol 172:1263-1276.

Shizu R, Shindo S, Yoshida T, and Numazawa S (2012) MicroRNA-122 downregulation is involved in phenobarbital-mediated activation of the constitutive androstane receptor. PLoS One 7:e41291.

Smutny T, Mani S, and Pavek P (2013) Post-translational and post-transcriptional modifications of pregnane X receptor (PXR) in regulation of the cytochrome P450 superfamily. Curr Drug Metab 14:1059-1069.

Søkilde R, Newie I, Persson H, Borg A, and Rovira C (2015) Passenger strand loading in overexpression experiments using microRNA mimics. RNA Biol 12:787-791.

Staudinger JL, Goodwin B, Jones SA, Hawkins-Brown D, MacKenzie KI, LaTour A Liu Y, Klaassen CD, Brown KK, Reinhard J, et al. (2001) The nuclear receptor PXR is a lithocholic acid sensor that protects against liver toxicity. Proc Natl Acad Sci USA 98:3369-3374.

Staudinger JL, Xu C, Biswas A, and Mani S (2011) Post-translational modification of pregnane $\mathrm{x}$ receptor. Pharmacol Res 64:4-10.

Takagi S, Nakajima M, Mohri T, and Yokoi T (2008) Post-transcriptional regulation of human pregnane $\mathrm{X}$ receptor by micro-RNA affects the expression of cytochrome P450 3A4. J Biol Chem 283:9674-9680.

Takahashi K, Tatsumi N, Fukami T, Yokoi T, and Nakajima M (2014) Integrated analysis of rifampicin-induced microRNA and gene expression changes in human hepatocytes. Drug Metab Pharmacokinet 29:333-340.

Tegude H, Schnabel A, Zanger UM, Klein K, Eichelbaum M, and Burk O (2007) Molecular mechanism of basal CYP3A4 regulation by hepatocyte nuclear factor $4 \alpha$ : evidence for direct regulation in the intestine. Drug Metab Dispos 35:946-954.

Vachirayonstien T and Yan B (2016) MicroRNA-30c-1-3p is a silencer of the pregnane $\mathrm{X}$ receptor by targeting the 3 '-untranslated region and alters the expression of its target gene cytochrome P450 3A4. Biochim Biophys Acta 1859:1238-1244.

Vreugdenhil E, Verissimo CS, Mariman R, Kamphorst JT, Barbosa JS, Zweers T, Champagne DL, Schouten T, Meijer OC, de Kloet ER, et al. (2009) MicroRNA 18 and 124a down-regulate the glucocorticoid receptor: implications for glucocorticoid responsiveness in the brain. Endocrinology 150:2220-2228.

Wang Z, Yao H, Lin S, Zhu X, Shen Z, Lu G, Poon WS, Xie D, Lin MC, and Kung HF (2013) Transcriptional and epigenetic regulation of human microRNAs. Cancer Lett 331:1-10.

Wei Z, Chen M, Zhang Y, Wang X, Jiang S, Wang Y, Wu X, Qin S, He L, Zhang L, et al. (2013) No correlation of hsa-miR-148a with expression of PXR or CYP3A4 in human livers from Chinese Han population. PLoS One 8:e59141.

Xie W, Barwick JL, Downes M, Blumberg B, Simon CM, Nelson MC, NeuschwanderTetri BA, Brunt EM, Guzelian PS, and Evans RM (2000) Humanized xenobiotic response in mice expressing nuclear receptor SXR. Nature 406:435-439.

Yeung EYH, Sueyoshi T, Negishi M, and Chang TKH (2008) Identification of Ginkgo biloba as a novel activator of pregnane $\mathrm{X}$ receptor. Drug Metab Dispos 36: $2270-2276$.

Zhang SY, Surapureddi S, Coulter S, Ferguson SS, and Goldstein JA (2012) Human CYP2C8 is post-transcriptionally regulated by microRNAs 103 and 107 in human liver. Mol Pharmacol 82:529-540.

Zhu X, Yang Y, Han T, Yin G, Gao P, Ni Y, Su X, Liu Y, and Yao Y (2015) Suppression of microRNA-18a expression inhibits invasion and promotes apoptosis of human trophoblast cells by targeting the estrogen receptor $\alpha$ gene. Mol Med Rep 12:2701-2706

Address correspondence to: Dr. Thomas K. H. Chang, Faculty of Pharmaceutical Sciences, The University of British Columbia, 2405 Wesbrook Mall, Vancouver, British Columbia, V6T 1Z3, Canada. E-mail: thomas.chang@ ubc.ca 